\title{
The Analysis of Landslide Based on Geographic Information System in Mon State, Myanmar
}

\author{
Chaw Chaw Khaing ${ }^{1}$, Thin Lai Lai Thein ${ }^{2+}$ \\ ${ }^{1,2}$ University of Computer Studies, Yangon
}

\begin{abstract}
Land use change can increase or decrease landslide susceptibility in the mountainous areas. In the hilly and mountainous part of Mon State, Myanmar, land use change has taken place due to land extractions and rock extractions. These activities can worsen the slope susceptible to sliding due to mostly the wounding of the mountain. So, every year take place the landslide in monsoon season. The objective of this study is to define the landslide risk areas in support of development planning, monitoring, and control of unstable areas. In this study, the mapping of landslides using Sentinel 2, research on their combination for discerning historical landslides in the raining season. Landslide samples were obtained from the old landslide, road structure from the topo map and slope can get form digital elevation model (DEM)). Layers were analyzed and the average weighted score was applied to calculate every 9 classes to predict the landslide. Overlay, geoprocessing and geostatistical techniques in geographic information systems (GIS) were used to discriminate these weighted subclasses into landslide features 6 levels of risk areas. Landslides in the Paung township and Melamine at Mon State which showed the prone area with the study.
\end{abstract}

Keywords: Landslide, Geographic Information System, Sentinel 2

\section{Introduction}

Landslides are one of the disasters and that occurred pagoda it was on the top of the mountain and near the highway road. A lot of landslides occurred in near river regions and in the mountain regions. Many major landslides always occurred in mining region, caused by human activity. This study has six major factors causing landslides have been analyzed in GIS, the weighted overlay method with each six factors combination to get susceptibility landslide map. Sentinel 2 image can evaluate the normalized difference vegetation index (NDVI) and the normalized difference water index (NDWI) value. In this study, histogram values are classified by 9 with Natural Breaks (Jenks) method. And land cover land use map used unsupervised classification with K-Means Algorithm.

\section{Study Areas}

The Paung hazard prone area is located in the south region of Myanmar. The Study area covers an area of about 603,332,510.665499 Square Meters between longitudes $9732^{\prime} \mathrm{E}$ and 97 33' E and between latitudes $1627^{\prime} \mathrm{N}$ and $16^{\circ} 32^{\prime} \mathrm{N}$. Fig 3. The entire area is located near the Thanlyin river and Gulf of Martaban. There are a lot of streams and the range of mountain regions. Land use land cover changes by the local company are extracts the land. This problem caused slope deformation and landslide. Fig. 1.

\section{The Data Source}

The data used in the study mainly include a topographic map for road pattern, a geological map for lithology, landslide reports for old landslide, sentinel 2 satellite $10 \mathrm{~m}$ resolution image. Sentinel- $2 \mathrm{~s}$ an Earth observation mission from the Copernicus programmed that acquires optical imagery with high spatial

\footnotetext{
+ Corresponding author. Tel.: + 9501 610655; fax: +013-610-633

E-mail address: chawchawkhaing@ucsy.edu.mm
} 
resolution $(10 \mathrm{~m})$ and systematic image, over land and coastal waters. This constellation mission has two twin satellites, Sentinel-2A and Sentinel-2B. It supports a large range of services and applications such as agricultural monitoring, emergency management, land cover classification or water quality. the European Space Agency (ESA) developed Sentinel-2 and operated, and Airbus Defense and Space (Airbus DS) manufactured satellites by a consortium led.
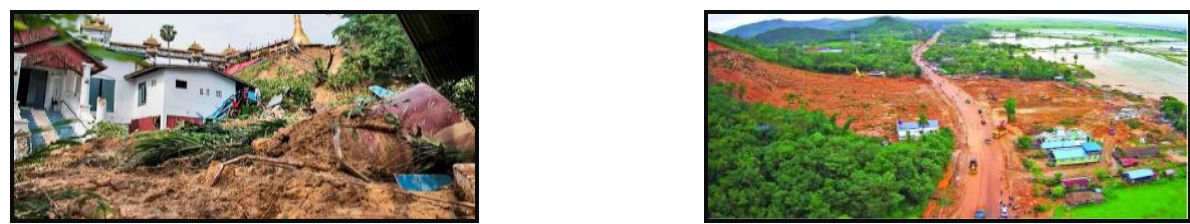

Fig. 1: Lower Myanmar, Paung and Melamine Township, Mon State

Table 1: Sentinel 2 satellite sensor specifications

\begin{tabular}{|l|l|l|l|}
\hline Band Name & Band Width $(\mathrm{mm})$ & Resolution & \multicolumn{1}{|c|}{ Purpose } \\
\hline Band 2 & 65 & 10 & Blue \\
\hline Band 3 & 35 & 10 & Green \\
\hline Band 4 & 30 & 10 & Red \\
\hline Band 5 & 15 & 20 & Vegetation Classification \\
\hline Band 6 & 15 & 20 & Vegetation Classification \\
\hline Band 7 & 20 & 20 & Vegetation Classification \\
\hline Band 8 & 115 & 10 & Near infrared \\
\hline
\end{tabular}

The metrological data (numeric data) can't get the update from the Department of Meteorology and Hydrology (Myanmar) and also USGS, now can get up to July, 2019. The study of the landslide was on 9 August 2019.

\subsection{Featured Based on Digital Elevation Model}

\subsubsection{Slope}

Slope degree is one of the most frequently-used factors in assessing landslide susceptibility. It has a great influence on slope stability and is directly related to the different types of mountain hazards. A slope is the rise or fall of the land surface. A slope is easy to recognize in a hilly area. Slope represents the rate of change of elevation for each digital elevation model (DEM) pixel. It represents the steepness of the surface and is symbolized into three classes that are shown using color saturation (brightness). Figure 2.

\subsubsection{Aspect}

The slope aspect is defined as the direction of the terrain surface, such as north, northeast, west, southwest. It identifies the downslope direction of the maximum rate of change in value from each pixel to its neighbors. It can be thought of as the slope direction. The values of the output raster will be the compass direction of the aspect, represented by a hue (color). Figure 3 .

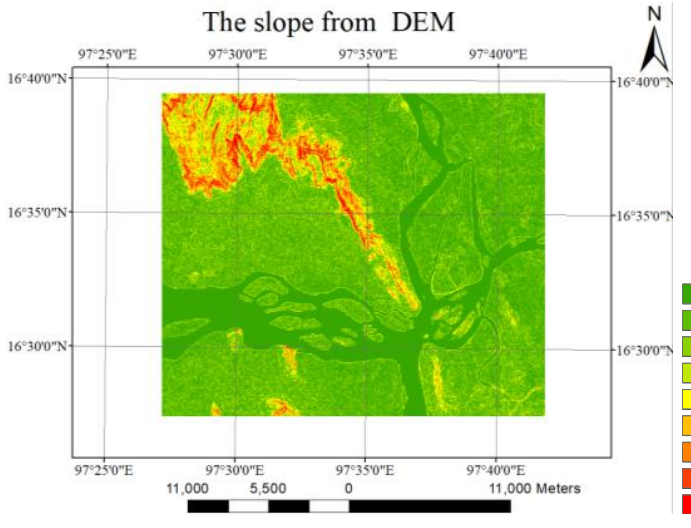

Fig. 2: The Slope

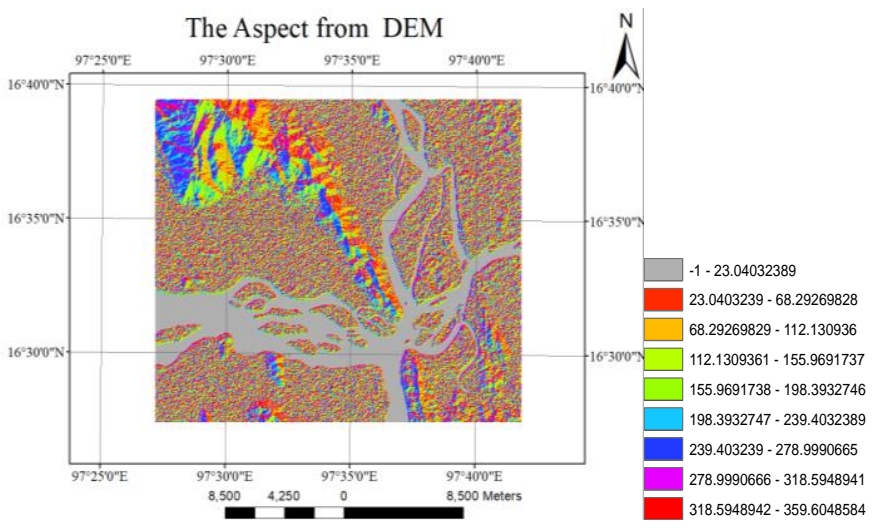

Fig. 3: The Aspect

\subsubsection{Contours}


Contours are lines that connect locations of equal value in a raster dataset that represents continuous phenomena such as elevation, temperature, precipitation, pollution, or atmospheric pressure. The line features connect cells of a constant value in the input. Contour lines are often generally referred to as isolines but can also have specific terms depending on what is being measured. Some examples are isobars for pressure, isotherms for temperature, and isohyets for precipitation. Fig 4.

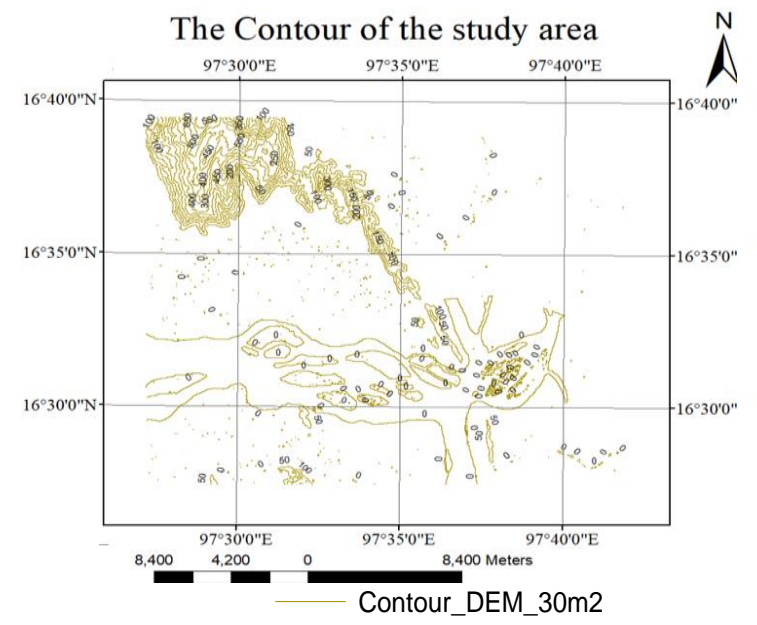

Fig. 4: Contour of the study Area

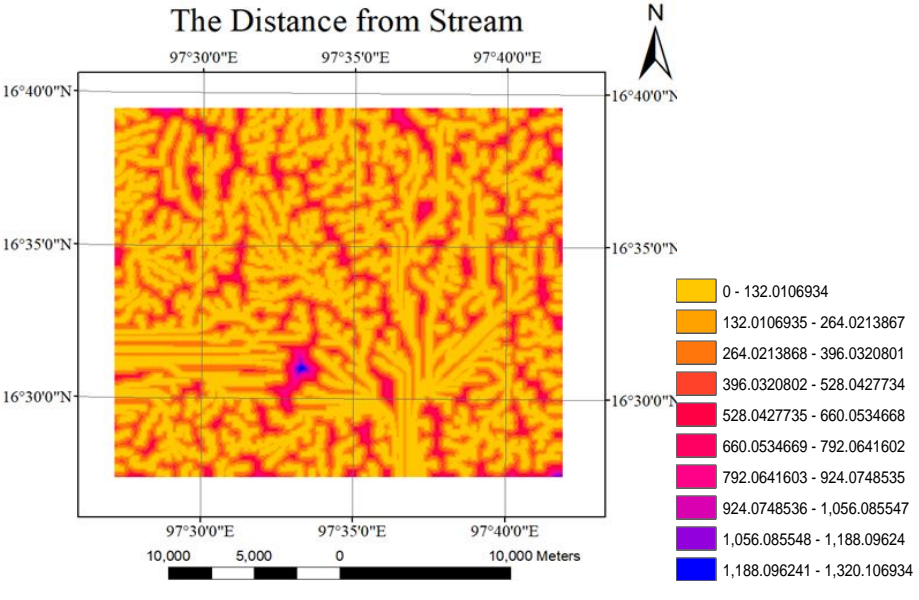

Fig. 5: Distance from Stream of the study Area

\subsubsection{Distance of Stream}

Stream Distance calculates from DEM using flow direction, flow accumulation, stream order. And to get the nearest distance stream use the Euclidean distance algorithm. The shortest distance to a source is determined, and if it is less than the specified maximum distance, the value is assigned to the cell location on the output raster. Fig 5.

\subsection{Featured Extract from Topo Map}

Road Distance calculates the road shape from topo map. And to get the nearest distance road also use the Euclidean distance algorithm. Fig 6.

\subsection{Feature Extracted from Remote Sensing Image}

Remote sensing images, geometric correction images are used to extract land cover and utilization information through object-based classification methods. This process used unsupervised classification and $\mathrm{K}$-means algorithm. Then different types of land covers are classified, tree, forest, agriculture, waterbody, road, open land and wetland.

\subsubsection{Distance of Stream Normalized Difference Vegetation Index (NDVI)}

The normalized difference vegetation index (NDVI) is a simple graphical indicator that can be used to analyse remote sensing images, images accessed by NDVI can interpret chlorophyll colour, so vegetation area is whether or not in the accessed images. Fig 7.

$$
N D V I=\frac{(N I R-R e d)}{(N I R+R e d)}
$$

Where NDVI stands for normalized difference vegetation index, NIR stand for nearest infrared band and Red stand for Red Band. NIR band and red band describe in table1, sentinel 2 satellite sensor specifications.

$$
N D W I=\frac{(\text { Green }-N I R)}{(\text { Green }+N I R)}
$$

Where NDWI stands for normalized difference water index, Green stands for green band and NIR stands for near infrared band. The green band describes in table 1, sentinel 2 satellite sensor specifications. Fig8. The classification results obtain vegetation index, NDVI index, NDWI index, road index, and stream index.

\subsection{Feature Based on Geological Map}

\subsubsection{Lithology}


The lithology and solid sources are upper Paleozoic (mainly C.P) Moulmein limestone [1]. The Nitsoil (NT) soil type is the World Reference Base for Soil Resources (WRB), this soil is a deep, red, well- drained soil. It contains more than $30 \%$ of a clay and structure is a blocky. This soil type correlate with the Kandic Alfisols, Ultisols and Inceptisols of the United States Department of Agriculture soil taxonomy.

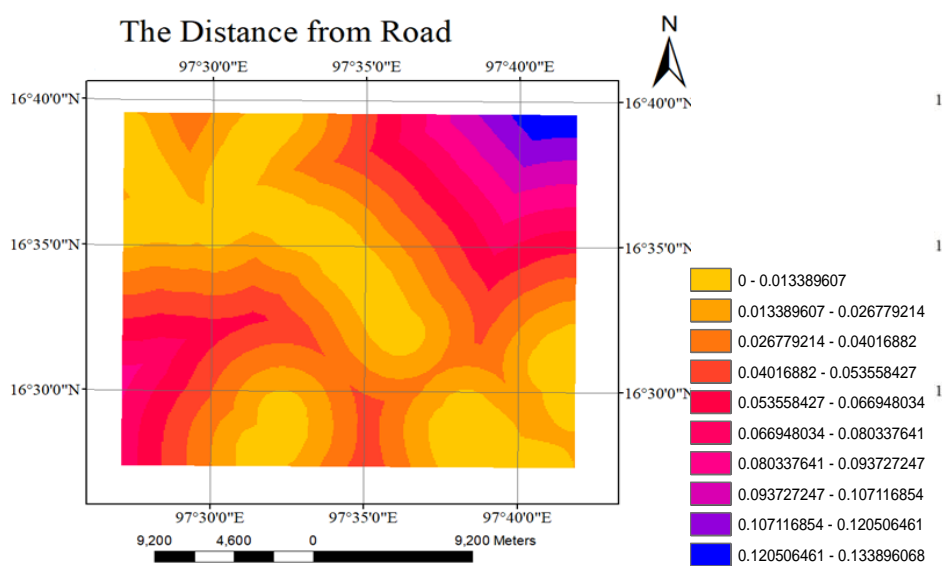

Fig. 6: The road distance map

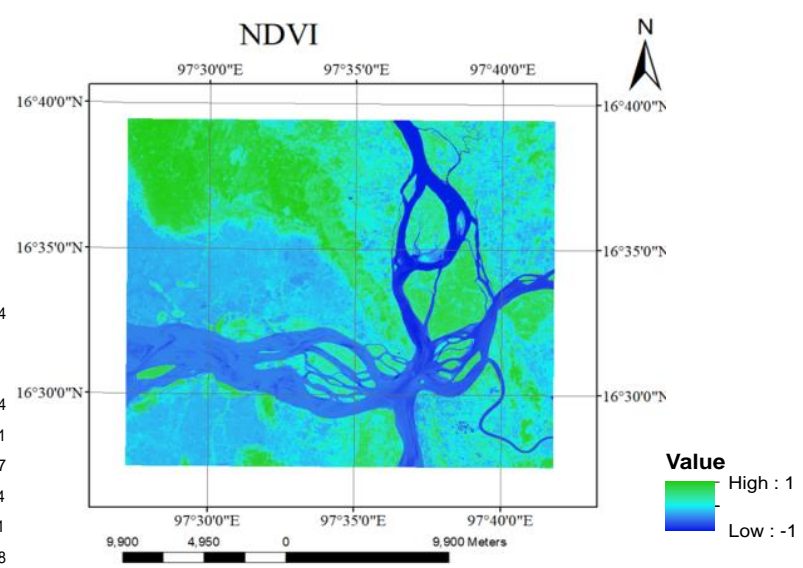

Fig. 7: NDVI

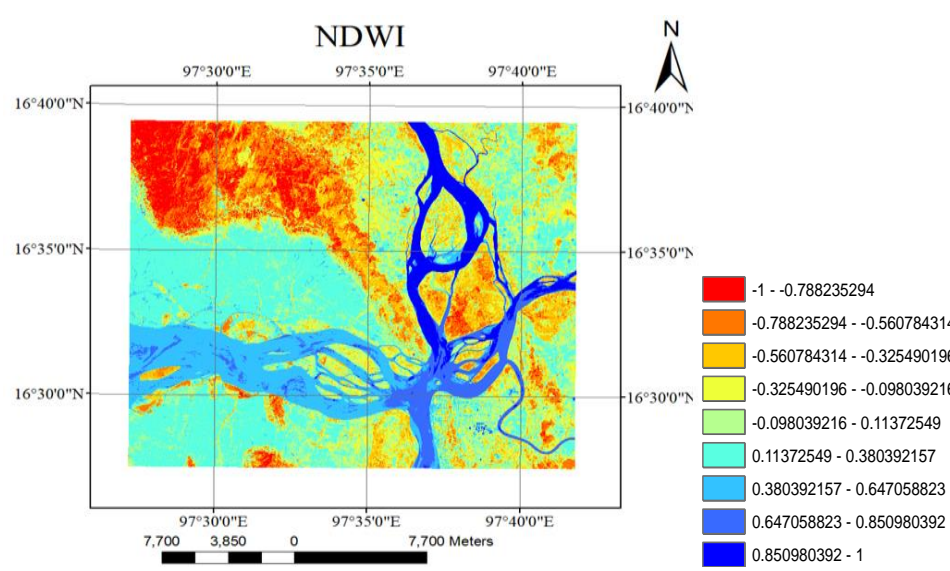

Fig. 8: NDWI

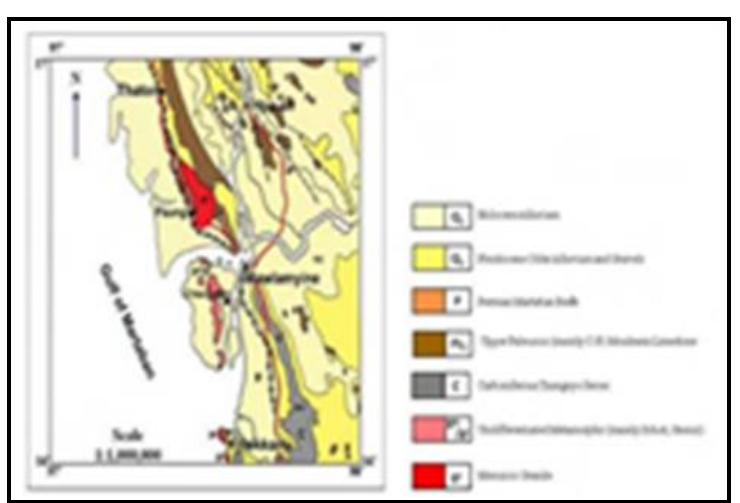

Fig. 9: Geological Map

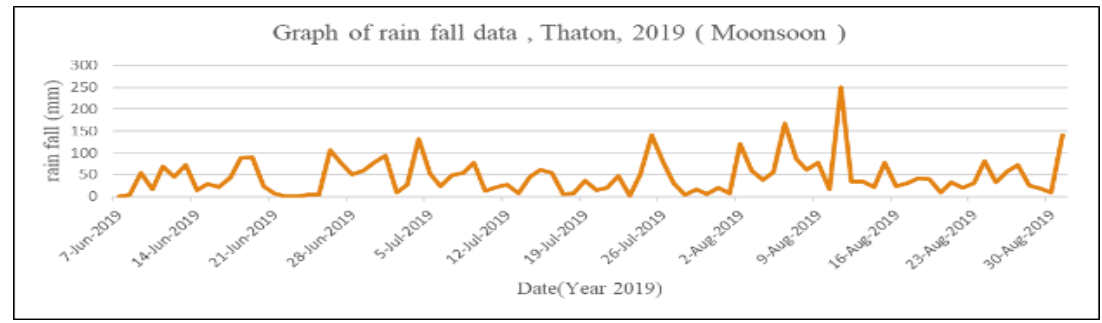

Fig. 10: Rainfall data

\subsection{Feature Based on Metrological Data}

Rainfall is an important factor in triggering landslides because it reduces soil suction and increases the pore-water pressure in soils [2]. This graph showed the landslide in the month June, July and August, during the monsoon season. This update data got from the local department, department of metrological and hydrology, Yangon, Myanmar. This graph showed the maximum rainfall day, this day occurred the landslide event.

\section{Experiment Result}

Deep learning algorithm, long short-term memory (LSTM) have four states, input gates, forget gates, cell units, output gates and learning the length of the input sequence data controls the number of the historical data points in the recursive connection. By the grid search method, the input sequence length is set to 6 with parameter is input sequence length and loss function [3]. 


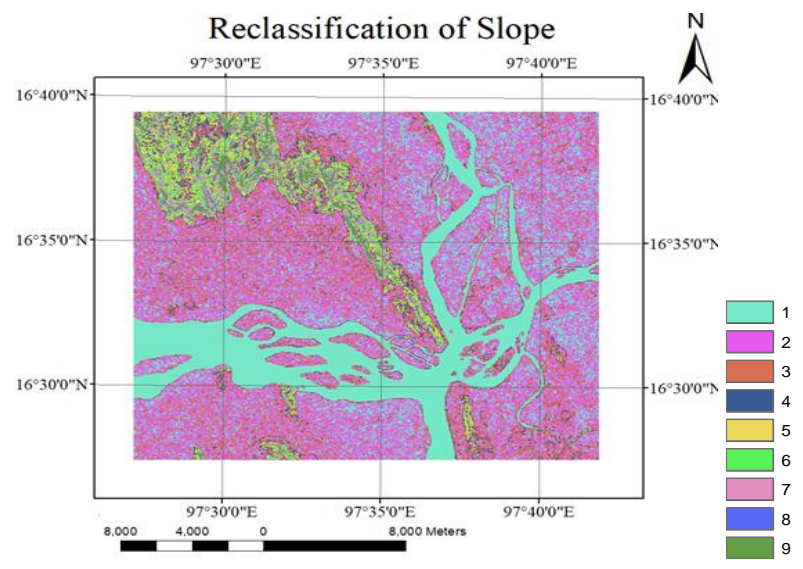

Fig. 11: Reclassification of Slope

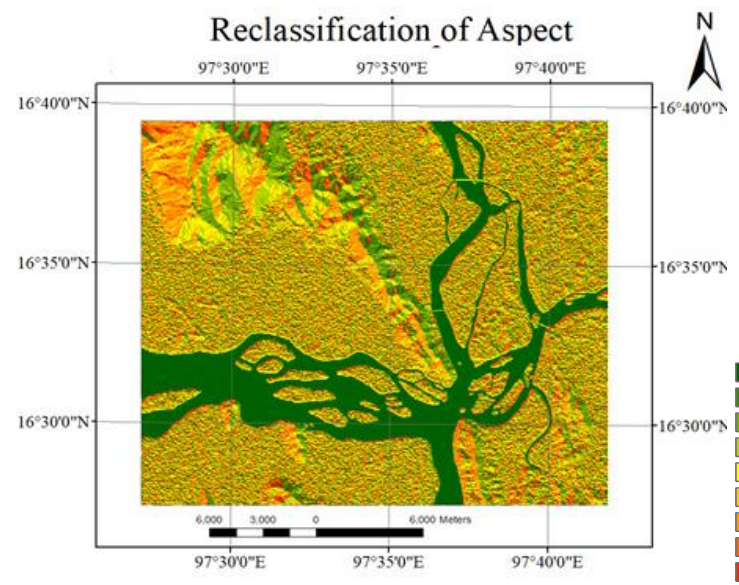

Fig. 13: Reclassification of Aspect

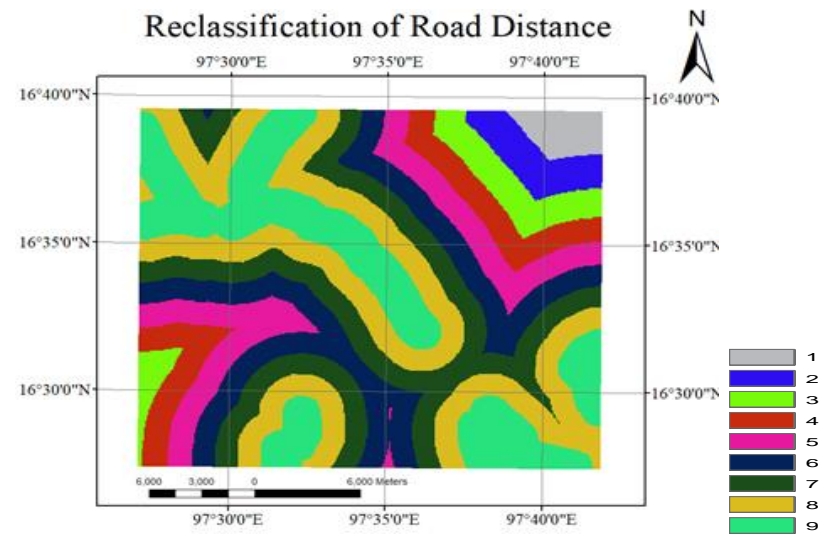

Fig. 15: Classification of Road distance

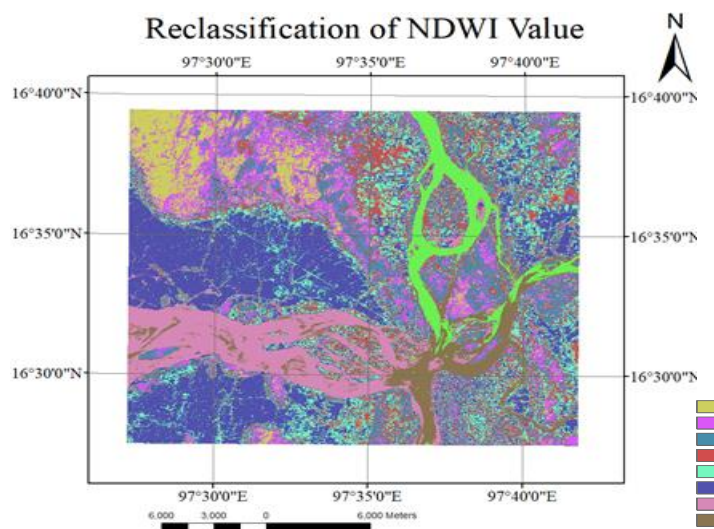

Fig. 17: Reclassification of NDWI value

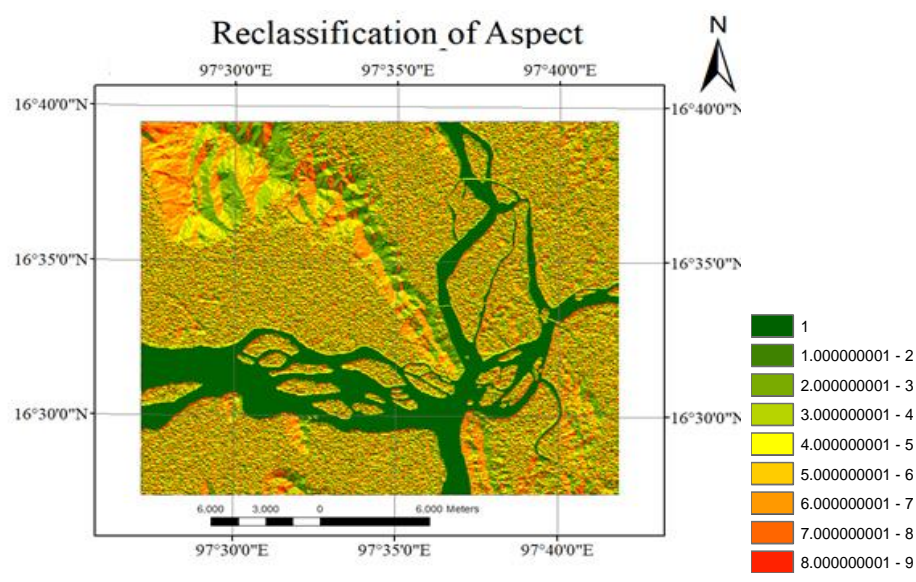

Fig. 12: Reclassification of Aspect

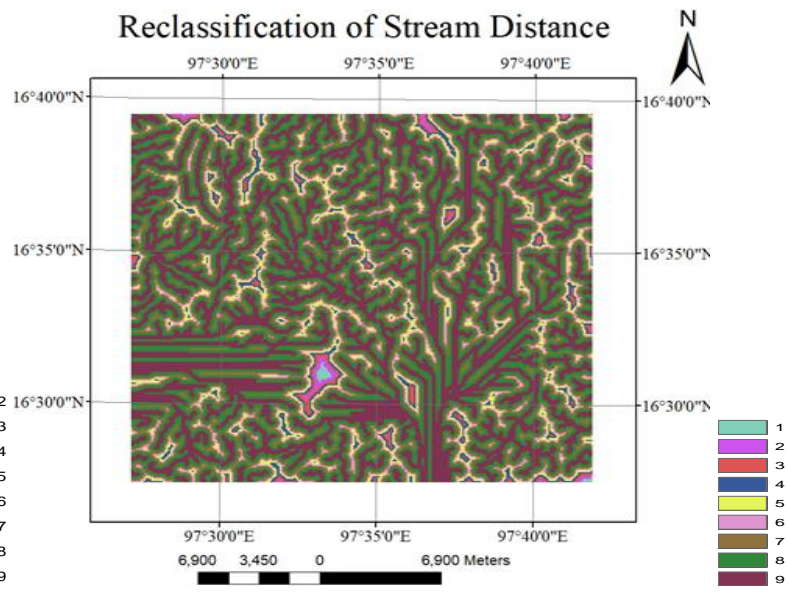

Fig. 14: Reclassification of Stream distance

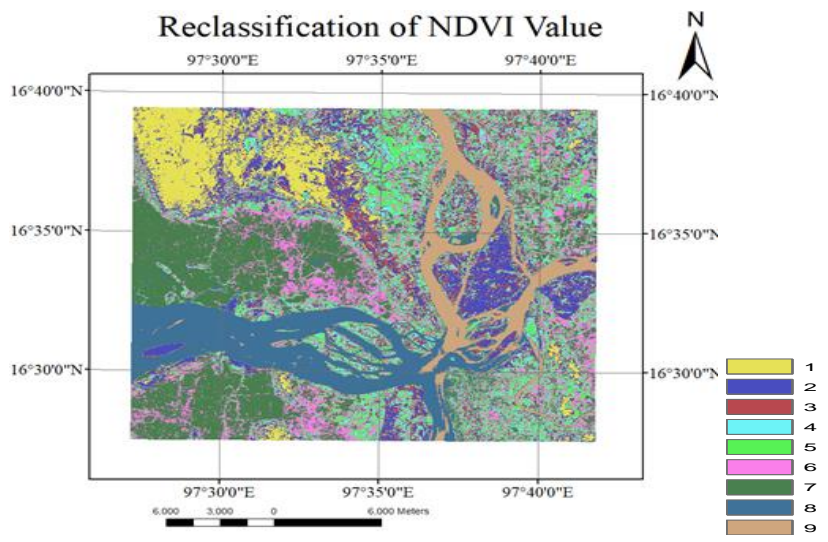

Fig. 16: Classification of NDVI value

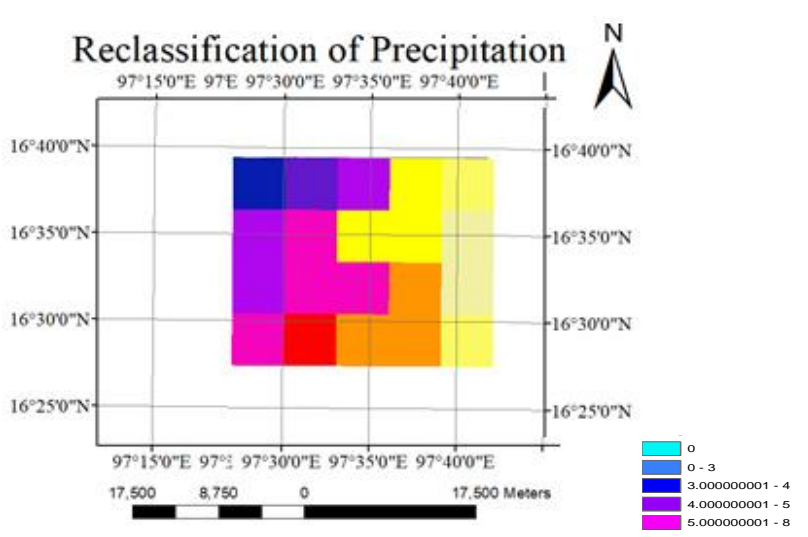

Fig. 18: Classification of precipitation 


\section{Result Output}
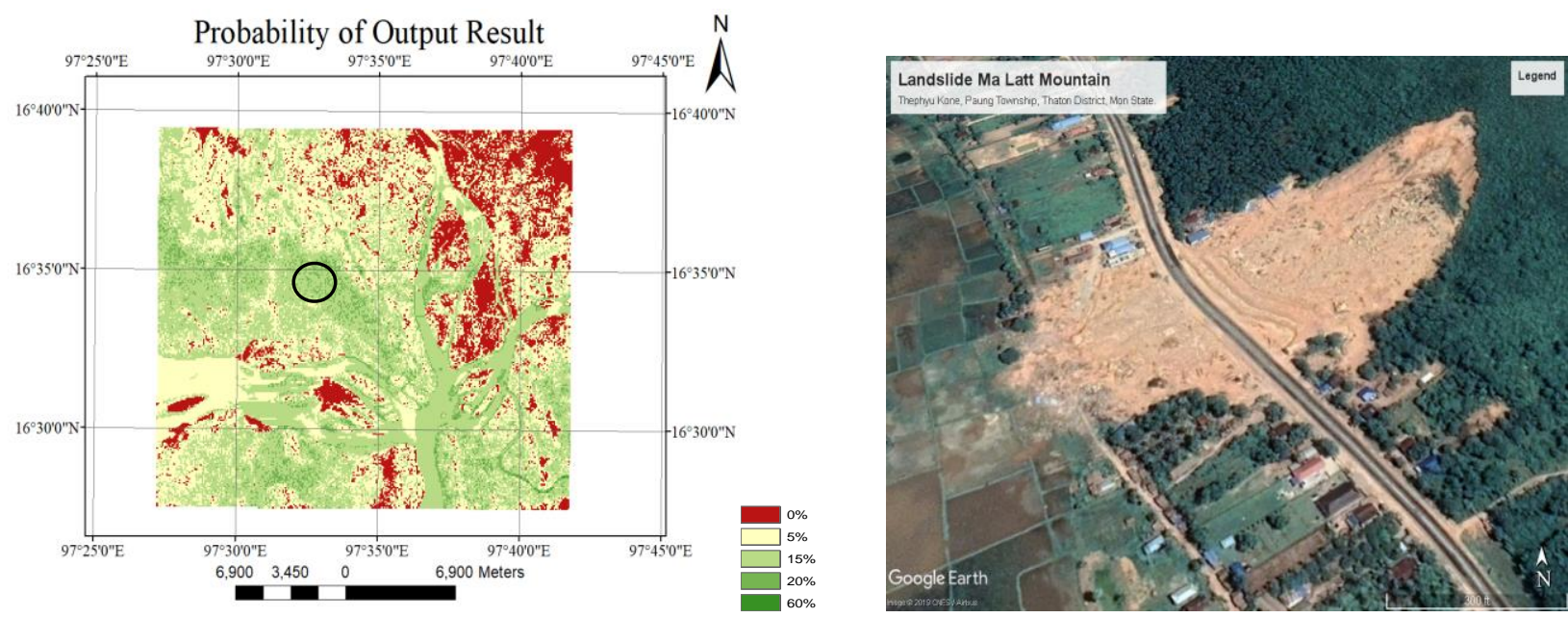

Fig. 19: Landslide Potential Map

\section{Conclusion}

The Paung township is a land extraction area of the Mon state. On the mountain and foot, the mountain has a lot of extraction. Due to this extraction, the natural environment decay and along with the hill wetland area increase on the mountain. Therefore, at least two days rainfall, on the top of wetlands are flowed under the mountain. This includes rock and clay, they are flowed. And then the foot of the mountain is very near the high way road, the stream, and river. This image can interpret the landslide prone area. The rainfall data from USGS, TRMM can get rainfall surface up to June, but this event took previous month of August. This historical data is proposed to solve the problem of landslide susceptibility. Geological data, geographic information, high-resolution remote sensing images, hydrological data can use features of LSTM model and predict the next disaster event during the moon soon, heavy rainfall two days. This historical product the model for real time monitoring system for landslide prevention. The other researchers construct the classification models with BPNN, SVM, and DT, which are also applied for comparisons with the LSTM model in landslide susceptibility assessments. The results of their study showed that the SVM model $(72.87 \%)$ had better accuracy than the BPNN $(62.03 \%)$ and DT model $(60.42 \%)$. The LSTM model (81.18\%) outperformed SVM in prediction accuracy [3].

\section{Acknowledgements}

I would like to thank my Supervisor, Dr. Thin Lai Lai Thein, Professor, the University of Computer Studies, and I would like to express thanks to Dr. Myint Myint Sein, GIS Lab, the University of Computer Studies, Yangon, for allowing me to develop of study and giving me general guidance during the period of my study. I would also like to express my respectful gratitude to Dr. Sabai Phyu, Professor, Dean of the Ph.D. 11th batch, the University of Computer Studies, Yangon, and Saya U Win Ko for their patient supervision, tenderness, encouragement and providing me. I would like to express my respectful gratitude to all my teachers for their encouragement. I also thank my friends from the Ph.D.11th batch for their co-operation and encouragement.

\section{References}

[1] Min Min Khaing. Petrological Analysis of the Granitoid Rocks from Pangon Area, Paung Township, Mon State. Dagon University Commemoration of 25th Anniversary Silver Jubilee Research Journal 2019, Vol.9, No.2 384.

[2] Tuhua Ma, Changjiang Li, Zhiming Lu, BaoxinWang. An effective antecedent precipitation model derived from the power-law relationship between landslide occurrence and rainfall level. Geomorphology 216 (2014) 187-192.

[3] Liming Xiao, Yonghong Zhang and Gongzhuang Peng. "Landslide Susceptibility Assessment Using Integrated Deep Learning Algorithm along the China-Nepal Highway", Sensors, MDPI. 